Comparative Philosophy Volume 11, No. 1 (2020): 32-45

Open Access / ISSN 2151-6014 / www.comparativephilosophy.org

https://doi.org/10.31979/2151-6014(2020).110106

\title{
A NEW MATERIALISM: A READING OF THE NEW ART FROM CHINA
}

\author{
MARY WISEMAN
}

\begin{abstract}
This essay has three parts. The first moves from what artists confronted when China was first opened to the west in 1978 to what two classical Chinese critics and artists said art was and how it was to be made. The second looks at artists' works made between two exhibitions in the United States, one in 1998, the other in 2017, to find an uncanny reprise of the classical principles. The third looks at the ideas of the global, contemporary, and art through the works of Peter Osborne and Arthur Danto that apply to the new art from China.
\end{abstract}

Keywords: aesthetics, contemporary, Danto, global, material, new art from China, western

When words fail, the world is not lost. It is there where matter and gesture, texture and touch reign, where the concrete, the particular, and the material are, and where life is. Something is happening in the art world of China in the first decades of the century that promises to make a difference to a globalized art world. Two independent movements overlap in a way that is likely to reconfigure the art of the 21 st century along lines being drawn by this new art from China. It has to do with material and with the stories that wrap around particular things: everyone understands both. The one movement is from the focus on language as what determines how we articulate ideas and see the world to a focus on what underlies, transcends, hides within language that we try to get at by reading through, below, or beyond its words. What is outside language is the material world of space and time with its quarks and black holes, electrons, protons, and neutrons, earth, air, fire, and water, natural kinds, artificial kinds, and individuals that are one of a kind. The turn from the linguistic to the material is the end of a line in the west that moves from Descartes' cogito through Freud's unconscious on to the body with its senses and network of nerves, where nerves are interfaces with the world more sensitive than senses. Neuroscience is their study. The material turn is a western one, but the Chinese have a reason to go below the levels of language: the presence in their world of the conflicting discourses of communism and capitalism and the nearby presence

WISEMAN, MARY: Professor of Philosophy Emeritus at Graduate Center, City University of New York, USA. Email: marigold21@comcast.net 
of Britain in Hong Kong and pre-revolution China in Taiwan.

The material turn of the new art from China is worthy of study for two reasons that have to do, respectively, with history and metaphysics. First, the change from communist to communist-capitalist China was abrupt, as the one from classical to communist China was not. The cut was as deep as it was sudden, but it did not go all the way down. Murmurs of the emperors and of Mao can be heard and provide an example of the past persisting even though it has been put out of sight. Second, the material used in the new art is either an individual like a train damaged in the 2008 Sichuan earthquake or a kind of thing like the marks left by explosions of gunpowder. Often the material is also the subject of the artwork, what it is about, and is that to which the work calls attention. The call is to "look at this," where the "this-ness" of the subject is what the viewer is to appreciate and to wonder at, confronting it directly through its material, bypassing language. Turn now back to the two overlapping movements. The second movement that overlaps with the material is globalization whose current phase began with capitalism's search for raw materials and new markets and has, for a spate of reasons including the existence of the internet, come to include art. The two movements overlap because material, the other side of language, is a least common denominator and is understood across the globe. We all live in a material world. The materialism of the art from China makes it accessible, and its Chinese-ness, the stories about its materials, makes it interesting. What the art's materialism consists in can be seen in exhibitions of new work by Chinese artists brought into this country. Two exhibitions are of special interest.

In 1998 Gao Minglu, the curator of the exhibition Inside Out: New Chinese Art, said that the paradox of trying to present the originality of new Chinese art on its own terms in so different a setting as New York may best be described by the title of the exhibition, Inside Out. (Emphasis added.) The exhibition's settings were the Asia Society and P. S. 1 Contemporary Art Center, Long Island City, New York. It introduced the new art from China to the United States, much as the Armory Show in New York in 1913 introduced modernism. Almost twenty years after Inside Out, in 2017, Art and China after 1989: The Theater of the World was mounted by the Guggenheim Museum. So far from there being a tension between the New York museum world and the new Chinese art in its originality and on its own terms, the claim is made by Alexandra Munroe, one of the exhibition's curators, that this art should not be part of a Sino-centric narrative but of a global one. It is at home anywhere.

This essay takes a brief look at what happened in the twenty years between Inside Out and the Guggenheim exhibition in light of what has been shown in these exhibitions and many others shown in the United States and seen through the lenses of Peter Osborne's conception of the contemporary and Arthur Danto's definition of art. What we see in the art does not take us to sociology or the study of visual or material culture, but to philosophy: to epistemology. ethics, and metaphysics. The new art is a path to knowledge about its subject, takes itself to have an ethical charge, and redraws the lines along which artworks are delineated. The presence of philosophy is reinforced by the interest of some Chinese artists in Taoism and Buddhism and by some of the artists reading widely in western philosophy. What follows speaks to works made in 
the years between the two exhibitions and to this growing awareness of how different is its tenor from that of the art whose family tree is modernism. This different tenor is part of what makes the new Chinese art interesting to a western audience. What underlies the material and its stories had been little known to many in the west. Begin by addressing the art made in the throes of the changes China was undergoing after the death of Mao in 1976 and end by seeing the new Chinese art as emblematic of an art contemporary, Chinese, and global.

\section{CRISIS}

Look now at what artists in China went through when in 1978, bourgeois capitalism, the enemy of communism, was invited into China. Until then art had been limited to what furthered the revolution. Classical Chinese art had been forced into shadow; the greatest collection of it, that of the Imperial Palace, having been taken to Taiwan. Western art had been banned. If the artists about whom we are talking, all of whom had lived through the Cultural Revolution, wanted to make art that spoke to the new China, they were on their own. Or so it seemed. Part One claims that the art of those early years took upon itself to subvert certain beliefs or presumptions. Through their art artists sought to undermine, first, the presumption that the social space in which a communist government and a capitalist economy lived side by side was one in which they could be themselves and discover what it is to be Chinese in a world soon to go mad for money; second, the presumption that the discourses of each could interpret the other when, for example, one discourse celebrates the individual and the other wants the individual to submit to the state; and, third, that modernist conceptions and theories of art were adequate to the new art despite the differences in their conceptions of what art was supposed to do, of its purpose. Examples of the artworks through which this was done are found in Part Two below. It turns out, however, that once high modernism lost its authority, the plurality and focus on the particular and the local characteristic of postmodernism - rejected though it is by both Osborne and Danto - cohere nicely with the new art from China. Move now from the time soon after the opening to the west and the time long gone when the Chinese way of looking at the world took the form of instructions to painters about how to capture that world in their work through their contemplation of it.

Classical art might have gone to Taiwan, but there was still the influence, underground though it might have gone, of deeply entrenched views articulated in the fifth and seventeenth centuries by Hseith Ho and Shitao, respectively. Move from the subversion of certain received beliefs to the Chinese view of expression that unfolds in their writing. Material versions of their prescriptions appear in some of the best new art and contribute to making the art global. Classical and global are recto and verso as, in the east, are spiritual and material. We pit the Chinese view against the high analytic view of Monroe Beardsley (1915-1985) to underscore how spare his view is and how capaciousness is the Chinese.1 For Beardsley expression is a relation whose minimal

\footnotetext{
${ }^{1}$ Monroe Beardsley 1981.
} 
formulation he gives as "an artwork expresses a psychological state or quality." He goes on to say that we can usually say what we want to say without using "express," as in the work arouses joy in the viewer or the work is joyful. His final formulation includes the manner and medium of any expression: "something is expressed by someone in some way through some medium or other." This gives way to the broader view of Rudolf Arnheim (1904-2007) who allowed that more than only psychological states can be expressed and that objects as well as agents can express. His singular contribution to the discussion is to say that we cannot infer a work's history from what we see, but directly experience it as "forces and tensions present and active" in the object's visible shapes. ${ }^{2} \mathrm{He}$ is closer to the Chinese ancients than is Beardsley.

Hseith Ho (late fifth century) laid out six principles for painters to follow and was primarily concerned with what they should express, whereas the later Shitao was more concerned with how, which was through the One Stroke that he claimed to be the quintessence of the creative act. Here is the rendering of Hseith' Ho's principles by a critic who flourished in the mid-ninth century, Chang Yen-yuan, to whom Lin Yutang said we owe our knowledge of ancient Chinese history more than to anyone else. Chang Yen-yuan wrote:

Hseith Ho in ancient times said: 'What are the six techniques? First, creating a life-like tone and atmosphere; second, building structure through brush-work; third, depicting forms of things as they are; fourth, appropriate coloring; fifth, composition; sixth, transcribing and copying, ${ }^{3}$

Hseith Ho characterized the first principle as "Spirit Resonance (or Vibration of Vitality) and Life Movement," and this is more than creating a life-life tone and atmosphere. Life-likeness is a value sought and appreciated in the Renaissance and is what this principle asks the artist to capture, but there is more. It is the life, the vitality, the spirit of the particular object being painted, where "life" refers not to biology but to the this-ness, the essence, of the painted subject. It is close to what Gerard Manley Hopkins expresses in As Kingfishers Catch Fire when he wrote: each thing "finds tongue to fling out broad its name;/ Each mortal thing does one thing and the same:/ Deals out that being indoors each one dwells." 4

Shitao (seventeenth century), artist and critic, was a member of an imperial family in the Ming dynasty who became a recluse when the Manchus took the throne in 1644. Because by that time artists were slavishly copying the work of the masters, ignoring Hseith Ho's first five principles, Shitao wrote the Expressionist Credo to urge artists to be creative. Central to it was the One Stroke, the single creative act, that was what created method or law and difference out of a primeval chaos. Whereas in the Old Testament in the beginning was the word, in Shtiao's account the beginning was an action, the one stroke. An action, not a word, was what made difference and, hence, the world. In his account hills and streams are the interdependent and contrasting pair,

\footnotetext{
2 Rudolph Arnheim 1974, 412.

${ }^{3}$ Oswald Siren 2005,19.

${ }^{4}$ Gerard Manley Hopkins, As Kingfishers Catch Fire, in Catherine Phillips 2002, 122.
} 
rather than the opposing pairs in the west of, say, nature and culture, masculine and feminine, mind and body. Hills and streams, mountains and waters, bone and blood, comprise the universe:

For the mastery of the world is revealed only by the function of water, and water encircles and embraces it through the pressure of mountains. If the mountains and water do not come together and function, there will be nothing to circulate with or about, nothing ro embrace. And if there is no circulation and embracing, there will be no means of life and growth. ${ }^{5}$

There is here a grand materialism. Of the hills and mountains, Shitao says they are in him and he is in them, and with ink and brush he causes them to appear on paper.

\section{WORKING THROUGH ART}

Artists in the years between 1998 and 2017 used their art to work through issues raised by their strategic calling into question three things. One is their social space, how the presence of capitalism affects their sense of themselves as Chinese. Two is their language, what the source of language's meanings is. Three is their art and art theory, what is art's raison d'etre is if it is no longer to further the revolution. Questions about Chinese artists' relation to their past and to the west were rife. We now find artworks whose material is their subject, for example, dust from 9/11, ash from Buddhist temples, gunpowder, worms, the contents of a home, wood from the Qing dynasty, an old fishing boat, or works that are site specific, where the site is their subject, like the Three Gorges Dam in the Yangtse River. Here are examples of four forms in which matter is available to be the subject of a work of art: one, the material side of words, two, energy, three, material history, and, four, the woman's body.

\subsection{THE MATERIAL SIDE OF WORDS}

Xu Bing (b. 1955) made what is now an iconic work of late $20^{\text {th }}$ century art when he carved 4,000 wooden blocks with what look like bona fide Chinese characters but cannot be read. They mean noting. He printed and bound some into books as they would have been bound in the days of the emperors, papered walls with the pages and draped scrolls of them from the ceiling. It is Book from the Sky (1987-1991), the promise, but only the promise, of meaning. He made another work, The Living Word (2001), in which laser-cut acrylic characters for niao (bird) whose colors are those of the rainbow rose in New York's Morgan Library 50 feet in an undulating wave from floor to ceiling. The definition of "niao" was written on the floor from where the first character, the simplified version of the word, takes off to be followed by the traditional character, and so on through increasingly early forms to the earliest pictogram that ends with the form of the bird itself. Both of these works are dramatic callings of attention to the look, the

${ }^{5}$ Lin Yutang 1967, 156. 
shape, the material side, of the word. Material is particular and concrete, as are written and sounded words.

\subsection{ENERGY}

Where material and its movements reign, so does energy. The Daoist Zhuangzi (late $4^{\text {th }}$ century BCE) said that living things are not the only things that had qi, energy or spirit and that, indeed, cosmic yin and yang are the greatest of qi. Sulfur, charcoal, and potassium nitrate - gunpowder, invented in China in the $7^{\text {th }}$ century - and the energy they release is a signature of the art of Cai Guo-Qiang (b. 1957), which he began to ignite on canvas in 1985 . He wrote with fire. He chose it not only because it is an explosion of energy, but also because it is a hazard that produces an unpredictable splendor. In using it he is miming nature's being unpredictable, splendid, and potentially hazardous. His central idea is to use forces of natural energy to create works that connect both artist and viewer with the primordial and immediate states of chaos that are contained in the moment of explosion. The gunpowder drawings do not represent energy; the expenditure of energy is the artwork.

He also borrowed its power to mark and celebrate the Museum of Modern Art's temporary move from Manhattan to Queens in 2002 with Transient Rainbow, the first pyrotechnic event allowed in New York after 9/11. Cai choose to mark this with a rainbow, a thing of beauty caused by the sun's being refracted in droplets of moisture. The refraction causes the light to bend and all the colors of the world to appear in the sky, red in the outer and violet in the inner part of the arc. Whereas the airplanes' moving through the sky into the Twin Towers caused death and destruction, Transient Rainbow put beauty into the New York sky where death had been.

The energy of living things was harnessed by Cai and Xu Bing in an exhibition in 1998 called Between Heaven and Earth in the Bard Graduate Center in Manhattan in which Cai, in New York Earthworm Room (1998), added earthworms to tons of dirt, reprising Walter de Maria's New York Earth Room (1977), a room full of nothing but earth. The worms dug under the earth and after a time, things began to grow in it. Xu Bing's Silkworm Series (1998) was a room in which silkworms hatched, grew, and spun their threads over all in the room, a table and chair, a picture on the wall, a television set, a video recorder. Earthworms crawled under and silkworms over, but both left their mark.

\subsection{MATERIAL HISTORY}

Zhang Huan (b. 1965) has made artworks that uses material of malicious destruction, shards of Buddha statues destroyed in Tibet by the Red Guard during the Cultural Revolution (1966 to 1976) as well as material of reverential destruction, temple ash, the residue of incense burned in veneration of the Buddha. From the former he made statues of Buddha parts. His first included nine large copper fingers, where the fingers would have attached to a hand were small mesh cages, some of which had birds and tortoises in them, others had small cloth statues. One, Head from a Buddha Foot (2006), 
is distinctive in that the emerging head, out as far as the neck with its face down and chin on the ground, is a replica of the artist's head. He had used his body repeatedly early on in works of performance art and later in replicas; he returns to that here. The Buddha sculptures shown in New York's Asia Society in 2008 are all parts that metonymically stand for the whole. In reincarnating them as works of art, Zhang reincarnates the history and religion of which they are traces.

Zhang's use of the second sort of material history, material of reverential destruction, is found in his paintings made with temple ash. He made, for example, a series of ash paintings called Free Tiger Returns to Mountains (2002) as a plea to stop the predation of nature that is destroying the habitats of the South China tiger, the ancestor of all species of tiger, and in danger of extinction. They show the ethical dimension of much of the new art.

Finally, there is material history that is not the result of any kind of destruction, other than time, such as the many works that Ai Weiwei (b. 1957) makes out of wood, furniture, windows, and doors from the Ming and Qing dynasties.

\subsection{WOMEN'S BODIES}

It is through our bodies that we have our first, immediate, and most intimate encounter with matter. However, the body as such has not been of special interest in Chinese art and since this is so, neither has the nude been of special interest. In particular, the nude does not define a genre whose members portray the ideal human body, stripped bare, with nothing hidden because nothing to hide. With no past and no future--because it is an ideal--there is for the west's nude no becoming and no passing away: it exists only in the present and is fully present, as only Being is. ${ }^{6}$ Not only do representations of the unclothed human body not define a genre in the art of China, but the job for which the nude is conscripted in the west is not one the Chinese would choose. For on the Chinese view of the world, there is only what is not quite yet and what will be no longer, what is already starting to leave: there is no pure presence. There is, that is to say, only coming to be and passing away. Unlike depictions of the nude in western art, representations of the body in Chinese art do not stop the flow of the world and the passage of time. Nor is it, as Courbet's Origin of the World (1866) implies, the source of the world itself. ${ }^{7}$ The making, not the made, has traditionally been valued in the art of China, as it has been in its thought. Process, not product, and energy, not form, underlie and constitute the real. This is why the path of the flow of energy through the body, rather than anatomy, has been the lodestar of Chinese medicine, and why the human form does not have the role in Chinese art that it has in the art of the west.

\footnotetext{
${ }^{6}$ An elegant explanation of the absence is to be found in Francois Jullien 2007.

${ }^{7}$ Gustave Courbet, The Origin of the World, 1866, oil on canvas, 46 x $55 \mathrm{~cm}$. Paris, D’Orsay Museum. A naked female figure--cropped mid-thigh and below the shoulders--lies on the diagonal on a rumpled white sheet. The black background visible at the upper left corner of the picture plane and the woman's public hair are the only dark things. It is an anatomically detailed vagina, the origin of the world, to which the title alludes.
} 
Nevertheless, bodies are represented in paintings, photographs, and videos and are presented in performances in contemporary Chinese art, even though they do not call attention to themselves as such but to what they are doing or are being used to do. Experimental artists use the image or presence of the body to do what they have also used calligraphy to do, namely, divest the subject of their art of, or at least redirect the viewer's attention away from, its received meanings. As focus moved from the meaning to the look of the word, so focus moved from the meaning of an individual's life to its materiality. The sudden intrusion of the west into a society previously dominated by Mao and the values of the revolution unsettled the individual when the meanings that had dominated the society were put into limbo. Attention moved to the material side of the body, to the bare fact of it. Signifiers slip and slide over what they are supposed to signify, so values of communism and capitalism slid over and under each other. Contemporary China seems not to be intelligible at the level of discourse, and artists declare this by making works that enact the divorce of signs from their meanings.

What is the analogue with respect to the body of stripping language of its meaning? Since Chinese thought does not distinguish mind from body, which it holds to be as enspirited as mind is embodied, to divest the body of meaning is not to divest it of spirit or mind or to treat it as an empty shell, the corpse-like thing that Descartes held body to be. Not only is mind not distinct from body in Chinese worldviews, but neither is a person distinct from his or her social environment. Indeed, under Mao the raison d'etre of everyone was to serve the social collective. The idea that this is what gives individuals their meaning and purpose is being rethought in much of the new art of China. The question of what can be the purpose and source of meaning for a human life is what occupies and shapes much of the work of the avant-garde. The idea that a person exists for the state has not simply been replaced with the western Enlightenment notion of men and women as rational self-interested individuals who exist for themselves alone, however. The matter is more complicated, and more interesting.

The hard fact of the body, dependent as it is on food, water, air, and shelter, but not on a ready-made world, is one locus of artists' asking about where and how individuals can fit into a post-Mao China. What is on show now that the collective character of the body has been dealt a blow by the removal of the genderless Mao suit and the individual body comes into view? The body is being reworked through its representations in the new art in much the same way as is the Chinese language. Male artists use the body as a canvas or a prop, as Zhang Huan does in Family Tree (2001), a series of photographs that show his face being increasingly covered with the names of ancestors, with the last one showing his face completely covered in black ink. The work is, among other things, a play on the ancestors being written in him, in his genes, and on his face with their names. Once a sufficient number of names is written on his face, it is, he is, unreadable, a blank slate.

Female artists, on the other hand, have in severable noteworthy works attended to what the body does, to its flowering. One is Born with the Cultural Revolution (1995), a triptych of photographs by Xing Danwen (b. 1987) of a friend who was born in 1966, the first year of the Cultural Revolution. Like a western altarpiece, the center photo is 
almost twice as wide as the two side ones, the center one being the most important. Each photograph takes a different attitude toward pregnancy. The panel to the right shows the woman lying sensuously on a couch, under a painting of an odalisque, the panel to the left shows the woman in an office-like space attending to something there. The body of each figure in the side photographs is shown from her head to somewhere in her trunk, and each looks out at the viewer. The body of the woman in the larger center panel, however, is foreshortened, shown from the bottom of her pregnant belly to only the bottom of her face, obscured by her hair. Her pregnancy is the most important thing about her. There are pictures of Mao in all three, small ones in the two side panels and a large one, level with her nourishing breasts, in the center panel. The implication is that this is what women were valued for by Mao, their reproduction of workers. Yet the woman is faceless and cannot gaze out at the viewer as those in the side panels can. Mao valued women's bodies for what they alonr can do, and what they do for everyone, that is, they continue the species. This is different from their being valued for being able to satisfy men's sexual desires.

\section{THINKING THROUGH ART}

Peter Osbore's Anywhere or Not at All: Philosophy of Contemporary Art (2013) can be shown to apply to artworks in two exhibitions held in the United States in 2012. One, Ai Weiwei's According to What? at the Hircshhorn Museum in Washington, D. C. and the other, Lin Tianmiao: Bound Unbound at the Asia Society in Manhattan. The work of two artists in these exhibitions is quite different in that Ai Weiwei's work reaches out to the world, while that of Lin Tianmiao, who is a woman, is about covering and connecting, not opening up and reaching out. Osborne sees the contemporary as a modernism, of which he traces three stages. In the first, which began in the late $19^{\text {th }}$ century, the aesthetic reigned. In the second, genres, species of the genus art, took authority from the genus so that something could be a work of art only by belonging to an art genre. It was no longer sufficient for a work just to imitate the world or cause a certain pleasure to be art. It had to hew to the definitions of a genre to qualify. However, later in the $20^{\text {th }}$ century, genre boundaries began to blur. and genres too lost their authority. In what Osborne calls modernism's third stage, an individual work is no longer art by satisfying a definition of art or by satisfying conditions for belonging to a genre of art, but had to make the case for itself that it merited the name "art." Art had become contemporary. Works were on their own, rather as Chinese artists more or less were after China opened itself to western commerce and culture.

This is Osborne's history of the contemporary. His analysis is that to be contemporary an artwork has to be in the "historical present," not a magic moment of pure presence between past and future, but one redolent of the past. It must also have both aesthetic and discursive dimensions. That is, there has to be something to sense, and it has to be able to enter our conversation. Finally, it has to be for the present, which is to say that it must be of the present. A telling work, clearly for and of the present, from the Weiwei exhibition is Names of the Student Earthquake Victims Found by the Citizen's Investigation (2008-2011) in which the names of the students whose parents 
would give their children's names, which the government had refused to do for a year, are printed in black ink on white papers and hung on the wall in the first gallery of the exhibition in the Hirshhorn Museum. So far from remaining nameless, the children were further identified by having their birth years, gender, and class listed along with their names. A recording of the names, called Remembrance (2010), which takes three hours and 43 minutes, played continuously. This exhibit was made all the more poignant by the presence nearby of the Vietnam Veteran's Memorial (1982) by Maya Lin, which is two walls of polished black granite that meet at an angle and have carved into them the names of 58,000 soldiers killed in combat. Each work shows the materiality of language: the names are not only written or carved to be seen, but in Maya Lin's work the names are touched as well as seen and read.

Where Ai Weiwei reaches out, Lin Tianmiao turns in, philosophical to his political. The binding referred to in the exhibition's title refers to works in which every day small objects were bound in white thread in Bound and Unbound (1997) and, again, in All the Same (2011) where 260 of the bones in the human body were wrapped in silk the colors of the rainbow and shown in a 50 foot long line of bones in descending size. In a different register, in connection with a pair of installations of sculptures, one of five white statues of women and one of three pink statues of men, Chatting (2004) and Endless (2006), respectively, Lin Tianmiao said that: "The relationship between the men is more superficial; however, the relationship between the women is more primal, more instinctual, and sensitive'." 8 To be at the level of instinct is to be at the level of the body. However, it is not to the body, but to the fabric that covers it and the bones that shape it - to what is over and under the body-- that she turns in her art. She is functioning below the level of knowledge, below what she doubts, namely, "the knowledge constructed by a so-called woman's perspective and the pitfalls of female narrative language." " She has said also that the value systems of men and women are different. In an artist statement, Lin said that she wanted to explore "the subtle relationships of things in contrast, the conditions necessary for a shift from one aspect to another." 10

Her examples of contrast are big and small, gathering and scattering, aggression and withdrawal, harshness and tenderness, proliferation and reduction, and male and female. We add bound and unbound. The contrasts play out, she suggests, in the body, where the primitive and instinctual reign. It is where she goes to look for an answer to what she asked herself in New York, Who am I? The question arose as a result of the culture shock that New York gave her, to be repeated when she returned to China in 1995 to find that the artists who had been free to experiment before 1989, when she was in New York, were no longer free. Here too, the work is for and of the time and calls for conversation. Part of the history of which the historical present is redolent has to do with the causes for an artwork's being what it is. For Ai Weiwei's Names of the Student Earthquake Victims, it was the poor construction of the school buildings

\footnotetext{
${ }^{8}$ Melissa Chiu and Lin Tianmiao 2012, 18.

${ }^{9}$ Guo Xiaoyan 2012, 22.

${ }^{10}$ Melissa Chiu 2012, 22.
} 
compared with that of the nearby official and commercial buildings that withstood the quake. Part of the relevant history of Lin Tianmiao's work is her having had to roll into balls thread salvaged from worn out white cotton work clothes during the Cultural Revolution, as well as the challenge to her Chinese-ness posed by the introduction of the west into China.

Whereas the concept of the contemporary is critical--not everything made in the present is contemporary--that of the global is empirical. A work either does or not have a global appeal. A clearly necessary condition for a work of art's being global is that is has to be put before a global audience, but after its initial exposure to a worldwide audience, keeps that sort of audience only if it has some appeal for it. Often the appeal lies in of the material of new Chinese works and the stories behind it. The contents of Song Don's mother's home during the Cultural Revolution is the material and the subject of his installation Waste Not shown at New York's MoMA in 2009. The destruction of the villages and homes of millions of peasants as well as many cultural monuments caused by the Three Gorges Dam is the story behind the works by four artists working in different media in Wu Hung's curated Displacement: The Three Gorges Dam and Contemporary Chinese Art. Materials and stories are understood and appreciated by everyone, no matter where they live.

What the observation above that the classical and global were related as the recto and verso of a piece of paper referred to was this. The classical view that the artist is to open himself to the is-ness and the what-it-is-ness (existence and essence) of what he is to paint--where the essence reveals itself in the material, the immediately accessible part of a work--finds a counterpart in work whose material is its subject. In the new work it is the material to which the artist opens his body, either his body itself or its senses. Among works in which the former was the case are Printing on Water (1996), a performance by Song Dong in the Lasa River in Tibet in which he tried to print the character for "water" on the water by repeatedly bringing down onto the water a block on which the chraceter for water was carved, and Zhang Huan's To Raise the Water Level in A Fish Pond (1997). He did this by having a number of people stand in it chest high.

In The Real Thing (2007), one of the first exhibitions of new Chinese art in England, there are several striking works in which artists interact with mountains. A 2005 performance documented by video stills and photographs entitled 8848 Minus 1.86 (2005) consisted of the artist Xu Zhen's taking the measure of Mount Everest. The performance was accompanied by a text that began with a factual account of the Himalayas and ended with the report that the height of Everest, the tallest of the Himalayas, was set at 8848 meters in $1856 .{ }^{11}$ The account by Xu Zhen closed with the announcement that on May 22, $2005 \mathrm{Xu}$ Zhen and his team would climb Mount Everest and cut off its top; reducing its height by $186 \mathrm{~cm}$, Xu's height. To the casual viewer, the team carried it off successfully. We are being treated to a simulacrum of the real world, a fictional world, and $\mathrm{Xu}$ Zhen wants us to suspend disbelief and look at the

\footnotetext{
${ }^{11} \mathrm{Xu}$ Zhen takes this measurement to be authoritative even though an American team put a Global Positioning System on the highest bedrock in 1999 and found the mountain to be 8850 meters.
} 
video stills, documentary photographs, and refrigerated summit of Everest as though he really had imposed himself on the mountain. Was $\mathrm{Xu} Z \mathrm{Zhen}$ one with the mountain in his performance? Yes, deliberately to climb a mountain is to put oneself into intimate relation with it. In the simulacrum $\mathrm{Xu}$ Zhen did more than this, however. He left his mark on it by reducing its height by his own and, with that act, entered the history of the measurement of the height of the mountain. This hypothetical performance can be read either as an act of arrogant self-assertion in the face of a powerful nature or as a comment on how the exact measurement of the mountain does not touch its splendor or its sublimity. It is vast, and wonderful for that, regardless of whether it is more or less 1.86 meters. He became one with the mountain as the classical author had been instructed to do by quieting his mind and contemplating the mountain. Actions such as those the artists engaged in can be appreciated by audiences from any culture.

The new art is contemporary and it is global, but is it art? Has it made the case that it merits the name "art?" Let Danto make the case for it with his definition. ${ }^{12}$ But first note that his much vaunted "death of art" comes to no more than the claim that the art history driven by high modernism's quest for what made art a different kind of thing from anything else, artificial or natural, had ended with the answer made by art itself: "I am what I am and not another thing, dependent on myself and myself alone." Just then, as Danto tells it, Andy Warhol made Brillo Box (1964), a work that shouted its reference to, its dependence on, the commercial world of household aids. We can either say that Brillo Box is not art, the art world to the contrary notwithstanding, or that it is art and, therefore, modernist art history is not only over, but it is discredited, dead. Danto culled from Brillo Box and all the art there was, this definition: something is a work of art if is about something (is a representation) that figures in a rhetorical trope that the viewer is to interpret, and it has been made against a background of art history and art theory. This is to say that not only is something art by virtue of how it looks, but neither is it art by being a reality in its own right: "I am what I am and nothing else." It is art by virtue of what it does, which, according to Danto, is to show the viewer its subject in a new way, a way that enlightens, moves, or in some other way engages the viewer, and there are myriad ways to do this.

Neither the tradition, alive in a materialized form in the new art as in Zhang Huan's statues of parts of Buddha's body, nor the legacy of Mao that remains both in the tendency to credit all involved in a work's production and in the moral charge behind much art, nor the imports from the west such in China's Political Pop, send a clear signal to contemporary artists. Therefore, they are free to make works worth paying attention to, worth looking at and engaging with, works on which artist and audience collaborate as the audience interprets the rhetorical figure, usually a metaphor, that the artwork is. China and the west are both here in words about Ai Weiwei and in his own words:

${ }^{12}$ Arthur C. Danot 1954, 1981, and 1995. 
In Ai's case, the subject of his artistic practice is not his own authority or identity as the creator, but the physical nature of the materials he employs - the wood, stone, ceramics, and tea-or the immaterial and intangible skills and efforts of the executing craftsmen. ${ }^{13}$

Ai himself continues:

Rather than thinking of my projects as art; they attempt to introduce a new condition, a new means of expression or a new method of communication. If these possibilities didn't exist, I wouldn't feel the need to be an artist. ${ }^{14}$

Danto's definition of art, based as it is on the artwork's inviting the viewer to see reality in a new way by inviting her to see the subject of the art in a new way, fits happily with the new art from China and shows whatever can do this to be worthy of the name "art." 15

\section{REFERENCES}

Arnheim, Rudolph (1974), Art and Visual Perception: A Philosophy of the Creative Eye (Berkeley: University of California Press).

Beardsley, Monroe C. (1981), Aesthetic Problems in the Philosophy of Criticism, $2^{\text {nd }}$ ed. (Indianapolis: Hackett Publishing Company, Inc.).

Brougher, Kerry (xxxx), "Reconsidering Reality: An Interview with Ai Weiwei," in Ai Weiwei, According to What?, 16

Chiu, Melissa (2012), "The Body in Thread and Bone: Lin Tianmiao," in Bound Unbound, 22.

- (with Tianmiao Lin) (2012), "A Conversation with the Artist," in Bound Unbound: Lin Tianmiao (New York: Asia Society, 2012), 18.

Courbet, Gustave (1866), The Origin of the World, 1866, oil on canvas, 46 x $55 \mathrm{~cm}$. Paris, D’Orsay Museum.

Danto, Arthur C. (1954), "The End of Art: A Philophical Defencse," in History and Theory 37.4

- (1980), The Transfiguration of the Commonplace, (Cambridge: Harvard University Press).

- (1995), After the End of Art: Contemporary Art and the Pale of History (Princeton and Oxford: Princeton University Press).

Guo, Xiaoyan, "The Defiant Narratives of Lin Tianmiao," in Bound Unbound, 22.

Hopkins, Gerard Manley (1881), "As Kingfishers Catch Fire”, in Catherine Phillips (2002), Gerard Manley Hopkins: The Major Works including all the poems and selected prose (Oxford: Oxford University Press), 122.

\footnotetext{
${ }^{13}$ Mami Katoka 2012, 16

${ }^{14}$ Kerry Brougher 2012, 16

15 This essay is a prelude to and excerpts sections from my A Grand materialism in the New Art from China, forthcoming from Lexington Books.
} 
Jullien, Francois (2007), The Impossible Nude: Chinese Art and Western Aesthetics, trans. Maeve de la Guardia (Chicago and London: The University of Chicago Press).

Katoka, Mami (2012), "According to What?-A Questioning Attitude," in Ai Weiwei, According to What?, 16

Lin, Tianmiao (2012), Bound Unbound (New York: Asia Society).

Lin, Yutang (1967), The Chinese Theories of Art: Translations from the Masters of Chinese Art (New York: G. F. Putnam's Sons).

Siren, Oswald (2005), The Chinese on the Art of Painting: Texts by the Painter-Critics from the Han throughout the Ch'ing Dynasties (Peiping: 1936; reprint in Mineola, NY: Dover Publications, Inc.), 19. 